\title{
First Record of the Northern Italian Wall Lizard (Podarcis siculus campestris) in Missouri
}

\author{
Jeffrey T. Briggler ${ }^{1}$, Rhonda L. Rimer ${ }^{2}$, and Guntram Deichsel ${ }^{3}$ \\ ${ }^{1}$ Missouri Department of Conservation, Jefferson City, Missouri 65109, USA (jeff.briggler@mdc.mo.gov) \\ ${ }^{2}$ Missouri Department of Conservation, Springfield, Missouri 65803, USA (rhonda.rimer@mdc.mo.gov) \\ 3Biberach an der Riss, Germany DE-88400 (guntram.deichsel@gmx.de)
}

Photographs by the senior author.

$\mathrm{T}$ The Italian Wall Lizard (Podarcis siculus) is native to Italy and extreme southern Switzerland, including many islands in the Tyrrhenian Sea and along the Adriatic Coast. It is known as an invasive species (Kraus 2009) and thrives in habitats disturbed by human activities, especially rock walls, parks, gardens, cemeteries, and railyards (Burke and Deichsel 2008). Podarcis siculus has been successfully introduced to many locations in Europe (Arnold and Burton 1978; Henle and Klaver 1986) and multiple locations in at least six states in North America: California (Deichsel et al. 2010), Connecticut (Donihue et al. 2014), Kansas (Gubanyi 1999; Taggart 2004; Collins et al. 2010), New Jersey (Burke 2010), Pennsylvania (Kauffeld 1931), and New York (Mendyk 2007; Burke and Deichsel 2008; Mendyk and Adragna 2014). Herein, we document another successful introduction of $P$. s. campestris in Joplin, Missouri, representing the most southern latitude so far for the species in North America (Kraus 2009).

In September 2013, a resident of Joplin contacted the senior author concerning a large number of lizards "infesting" his neighborhood. Initial surveys revealed a thriving population. Interviews with local residents and follow up investigations determined that the lizards were accidentally introduced by a former resident of the neighborhood. In 2001, this resident obtained nine P. s. campestris from the Topeka, Kansas population with the assistance of a local herpetologist. These lizards were housed in a terrarium with a screen-wire lid. The lizards escaped when the terrarium was placed outside in the sun and overturned by a feral cat. The owner made numerous attempts to capture the lizards without success and thought that they would not survive the winter. However, by summer of 2002, the resident stated that he observed some youngof-the-year in the area and continued to see P. s. campestris until he moved out of the neighborhood in 2012. We identified the lizards as P. s. campestris (Fig. 1). Three voucher specimens were deposited at the Dean E. Metter Memorial Collection at the University of Missouri (UMC 8890-8892).
Robert Powell and GD confirmed the identity of the lizards from photographs and/or specimens.

We made four trips to the area to assess population size and distribution of P. s. campestris. Three surveys were conducted during autumn 2013. We observed a relatively large number of lizards ( 4 to 5 lizards within $10 \mathrm{~m}$ in some cases)

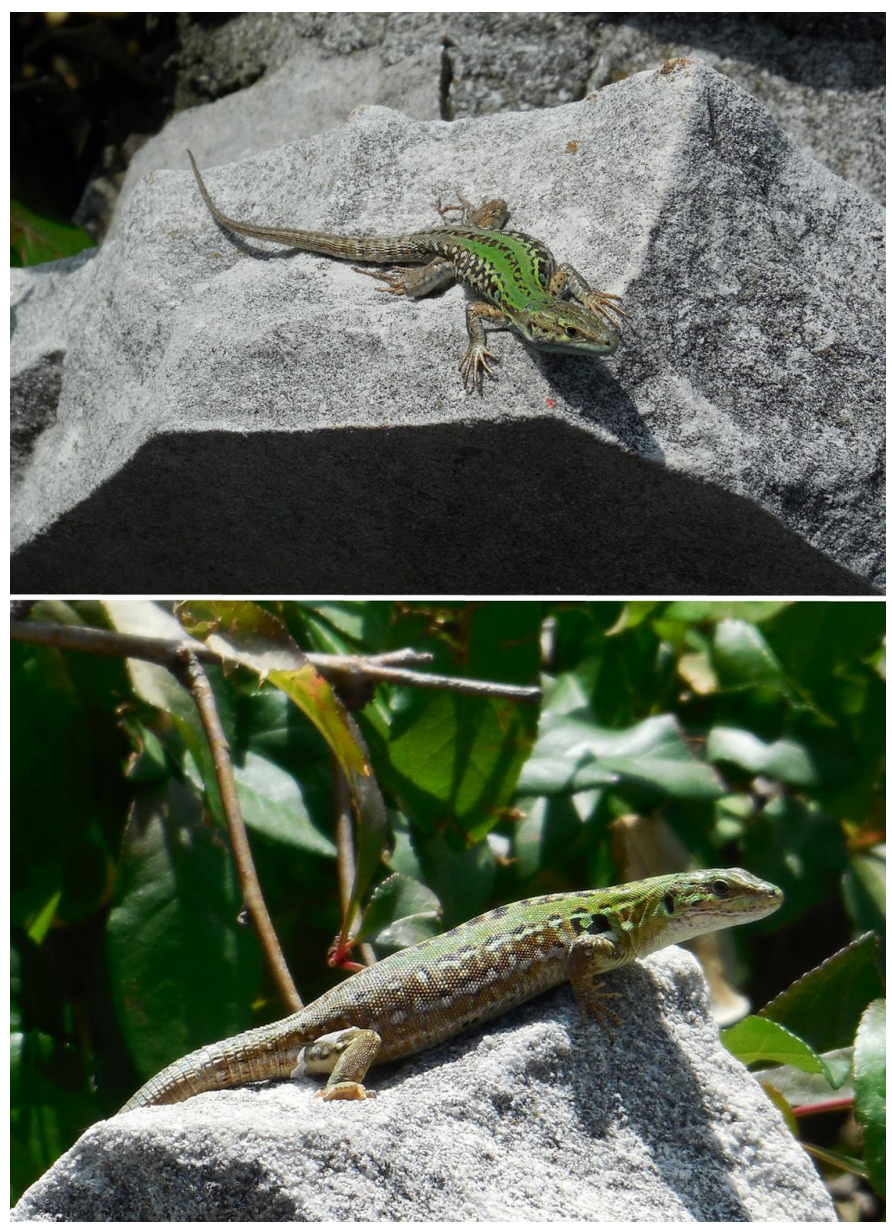

Fig. 1. Northern Italian Wall Lizards (Podarcis siculus campestris) in Joplin, Missouri: Adult male (top) and adult female (bottom). 
over several neighborhood blocks and captured 19 lizards on glue traps (Table 1). During spring 2014, we conducted an extensive survey throughout the neighborhood and observed 80 lizards of all size classes over a four-square-block area (Table 1, Fig. 2). NOAA ranked the Missouri winter of 20132014 as the tenth coldest on record (since 1895). Despite the extreme cold, the P. s. campestris population did not appear to be negatively impacted. Our observations indicate the species is well established. The affected neighborhood is one of the oldest in the city, with abandoned structures, and rock and concrete walls that provide ideal shelter for the lizards from both predators and cold temperatures (Fig. 3). In our surveys, we almost always saw lizards in rocky habitats such as on walls, sidewalks, or building foundations. However, we also saw individuals utilizing small burrows within lawns sometimes far from rock structures. Also, three P. s. campestris were captured on 2 December 2014 in a torpor state in a hollow section of the trunk of two Hackberry Trees (Celtis occidentalis) that had grown together and had been cut down. The hollow section was approximately $3 \mathrm{~m}$ above ground level. To

Table 1. Number of Northern Italian Wall Lizards (Podarcis siculus campestris) observed relative to search effort in Joplin, Missouri. ${ }^{1}=$ four individuals killed on glue traps; ${ }^{2}=15$ individuals killed on glue traps.

\begin{tabular}{lcc} 
Date & N & Effort $($ min.) \\
\hline 1 October 2013 & 10 & 20 \\
\hline 11 October 2013 & $6^{1}$ & 30 \\
\hline 28 October 2013 & $35^{2}$ & 70 \\
\hline 9 May 2014 & 80 & 237 \\
\hline
\end{tabular}

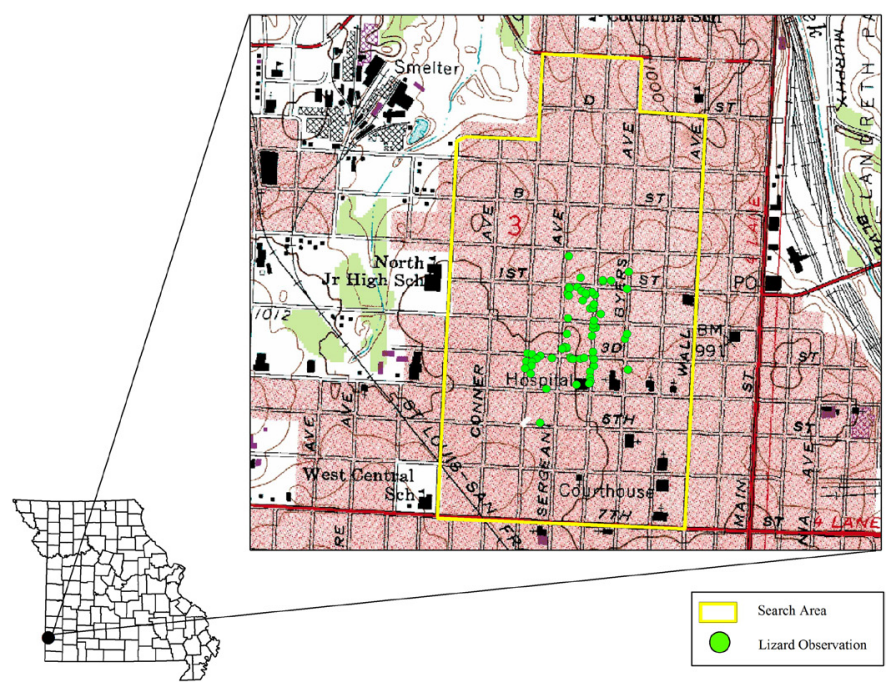

Fig. 2. Northern Italian Wall Lizard (Podarcis siculus campestris) distribution and search area in Joplin, Missouri.
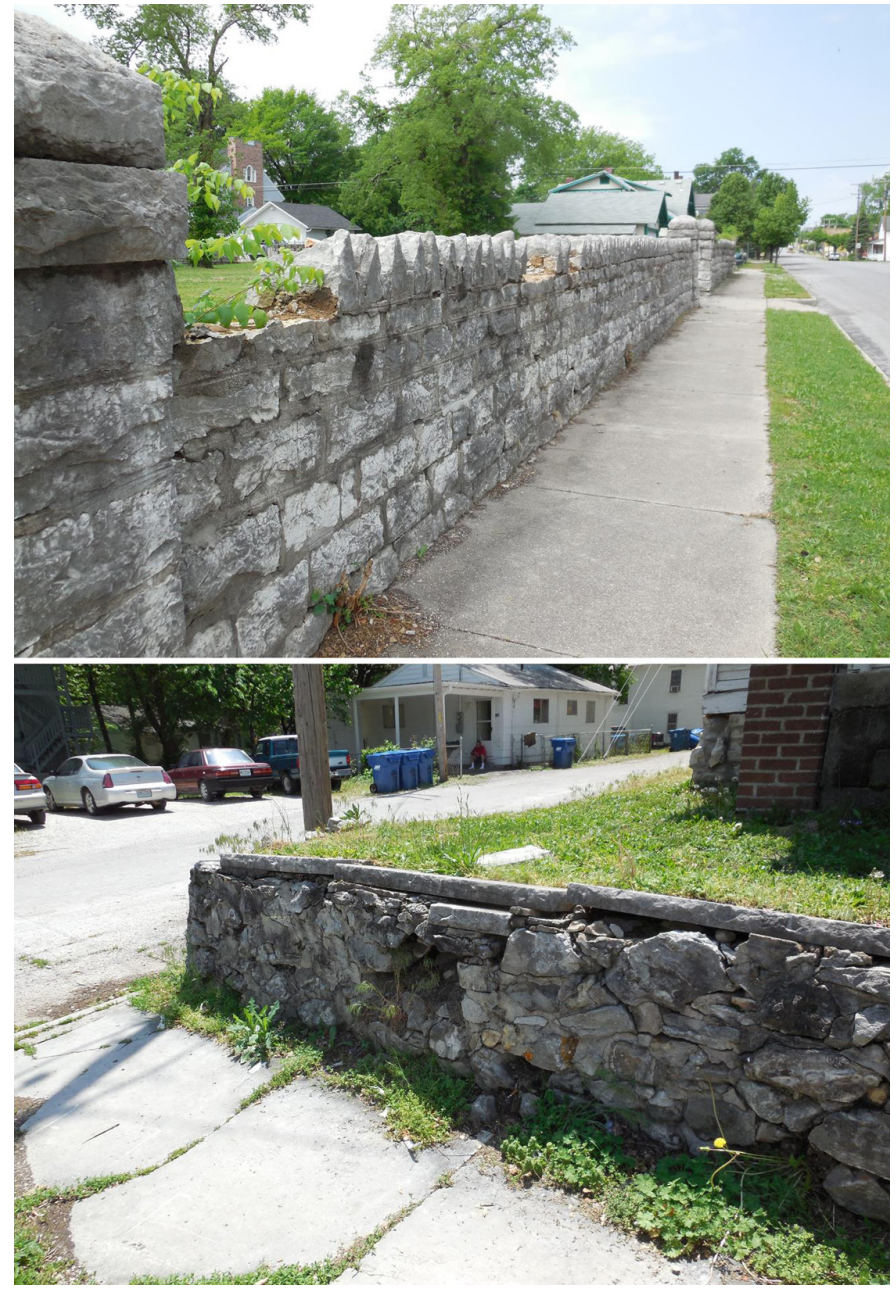

Fig. 3. Rock and concrete walls inhabited by the Northern Italian Wall Lizards (Podarcis siculus campestris) in Joplin, Missouri.

our knowledge, this is the first report of the species overwintering in a hollow tree trunk. As we expanded our searches outside the core area, stone walls became increasingly rare and feral cats appeared to be quite abundant. Feral cats are known predators of Podarcis species (Brown et al. 1995a, 1995b; Amo et al. 2004), and on two occasions, we witnessed cats stalking lizards. This might prevent the species from spreading outside this area.

Although laws in Missouri and many other states prohibit the release of non-native species to the wild, the majority of the introductions of P. siculus in the United States originated from the release of animals in the pet trade (Burke and Deichsel 2008; Kolbe et al. 2013). Burke and Deichsel (2008) also reported regularly receiving phone calls and e-mails from amateur herpetologists from states wanting to find locations to capture and release $P$. siculus, although many are aware that such actions are illegal. Even with laws in Missouri preventing the release of non-native species to the wild, this population of P. s. campestris became well established. Since this species is typically restricted to urban areas, we assume that 
competition and predation involving native lizards is likely to be minor. However, competition by P. siculus would likely occur with native lizards and other native wildlife on natural rocky outcrops called glades that are found in the general area and throughout the Ozark Highlands. These glades would likely support $P$. siculus, especially as the species ranges farther south into even more thermally favorable latitudes. Over the next several years, we will continue to monitor the population, distribution, and relative abundance of this exotic lizard in Joplin, Missouri, and continue to inform citizens of the threats such species can pose to native wildlife.

\section{Acknowledgments}

We thank S. Burger, M. Callihan, B. Jump, M. Phillips, and J. Wilkinson for assistance in surveys, reporting the introduction, and providing information on the introduction. Thanks to B. Butler and L. Davis for assistance with graphics. This work was funded and supported by the Missouri Department of Conservation.

\section{Literature Cited}

Amo, L., P. Lopez, and J. Martin. 2004. Multiple predators and conflicting refuge use in the Wall Lizard, Podarcis muralis. Annales Zoologici Fennici 41:671-679.

Arnold, E.N. and D.W. Ovenden. 1978. A Field Guide to the Reptiles and Amphibian of Britain and Europe. Harper Collins, London, UK.

Burke, R.L. 2010. Geographic distribution. Podarcis sicula campestris (Italian Wall Lizard). Herpetological Review 41:514.

Burke, R.L. and G. Deichsel. 2008. Lacertid lizards introduced into North America: History and future, pp. 347-353. In: J.C. Mitchell, R.E.J. Brown, and B.
Bartholomew (eds), Urban Herpetology. Herpetological Conservation, Volume 3. Society for the Study of Amphibians and Reptiles, Salt Lake City, Utah.

Brown, R.M., D.H. Taylor, and D.H. Gist. 1995a. Effect of caudal autotomy on locomotor performance of wall lizards (Podarcis muralis). Journal of Herpetology 29:98-105.

Brown, R.M., D.H. Taylor, and D.H. Gist. 1995b. Home range ecology of an introduced population of the European wall lizard Podarcis muralis (Lacertilia; Lacertidae) in Cincinnati, Ohio. American Midland Naturalist 133:344-359.

Deichsel, G., G. Nafis, and J. Hakim. 2010. Geographic distribution. Podarcis siculus (Italian Wall Lizard). Herpetological Review 41:513-514.

Collins, J.T., S.L. Collins, and T.W. Taggart. 2010. Amphibians, Reptiles, and Turtles in Kansas. Eagle Mountain Publishing LC, Eagle Mountain, Utah.

Donihue, C.M., M.R. Lambert, and G.J. Watkins-Colwell. 2014. Geographic distribution. Podarcis sicula (Italian Wall Lizard). Herpetological Review 45:661-662.

Gubanyi, J.E. 1999. Update on Lacerta in Topeka, Kansas. Kansas Herpetological Society News 118:113-14.

Henle, K. and C.J.J. Klaver. 1986. Podacris sicula, pp. 254-342. In: W. Bohme (ed), Handbuch der Reptilien und Amphibien Europas. Echsen III. Aula Verlag, Wiesbaden, Germany.

Kauffeld, C.F. 1931. Lacerta mellisellensis fiumana at Philadelphia. Copeia 1931: 163-164.

Kolbe, J.J., B.R. Lavin, R.L. Burke, L. Rugiero, M. Capula, and L. Luiselli. 2013. The desire for variety: Italian Wall Lizard (Podarcis siculus) populations introduced to the United States via the pet trade are derived from multiple nativerange sources. Biological Invasions 15:775-783.

Kraus, F. 2009. Alien Reptiles and Amphibians: A Scientific Compendium and Analysis. Springer Verlag, Dordrecht, The Netherlands.

Mendyk, R.W. 2007. An expanding population of Italian Wall Lizards in New York: Podarcis sicula campestris. Reptilia 55:65-71.

Mendyk, R.W. and J. Adragna. 2014. Notes on two introduced populations of the Italian Wall Lizard (Podarcis siculus) on Staten Island, New York. Reptiles \& Amphibians 21:142-143.

Taggart, T.W. 2004. Geographic distribution. Podarcis sicula. Kansas. Journal of Kansas Herpetology 10:10. 